\title{
Ecología y desarrollo humano integral
}

\section{Manuel López Casquete de Prado'}

Palabras clave: ecología integral, humanismo.

Key words: integral ecology, humanism.

Mots clés: écologie intégrale, humanism.

Uno de los conceptos clave en la evolución de la Doctrina Social de la Iglesia (en adelante DSI) desde el Concilio Vaticano II es el de desarrollo humano integral, introducido por Pablo VI gracias a la inspiración de la obra Humanismo integral ${ }^{2}$ del filósofo francés Jacques Maritain (1882-1973), a quien Pablo VI consideraba su maestro ${ }^{3}$.

Según McCauliff4, el pensamiento de Maritain fue particularmente útil en tiempos del Concilio. La visión compartida por Maritain y Pablo Vl era lo suficientemente sólida como para forjar lazos que facilitaran el trabajo relativo a la constitución de la Iglesia en el mundo moderno, la constitución pastoral Gaudium et spes de 1965.

${ }^{1}$ Departamento de Humanidades y Filosofía. Universidad Loyola Andalucía.

${ }^{2}$ Maritain, J. (1936) Humanisme intégral, París, Aubier.

3 Pablo VI afirmaba: "soy discípulo de Maritain; yo lo llamo mi maestro". Sobre esto, Evans, J. W. (1973) Jacques Maritain: Philosopher Was Pope's Teacher, Kansas City, National catholic reporter, p. 5, citado en MCCAULIFF, C. (2010) "The Friendship of Pope Paul VI and Jacques Maritain and the Declaration on Religious Freedom", Selected Works, New Jersey, Seton Hall University, p. 16.

${ }^{4}$ lbid, p. 5. 
Desde los primeros trabajos en el marco de la comisión preparatoria del Concilio, el Papa defendió las tesis expuestas por Maritain en su libro Humanismo integral.

A partir de Gaudium et spes, el concepto de desarrollo humano integral se asentó definitivamente en el acervo de la DSI, siendo además enriquecido y reelaborado en los sucesivos papados, y muy especialmente por Benedicto XVI en Caritas in veritate (2009). El n 8 de esta encíclica manifiesta que su propósito es homenajear, retomar y actualizar las enseñanzas de Populorum progressio de Pablo VI sobre desarrollo humano integral. De forma muy sintética, el contenido esencial de este concepto -tal y como lo plantea Maritain y es desarrollado por la DSI-contempla la existencia en el ser humano de una vocación o un dinamismo hacia un progresivo desarrollo que culmina con la apertura a la dimensión trascendente, donde el proceso de humanización se hace integral.

LS retoma el concepto de desarrollo integral, que usa con profusión. El término integral aparece en LS en veintinueve ocasiones, acompañando a sustantivos como ecología, progreso, mirada, política, y formación (además, obviamente, de aparecer frecuentemente junto al término desarrollo).

En términos generales, el calificativo de integral -en línea con lo expuesto anteriormente- alude a un dinamismo propio del ser humano que le conduce a un proceso de progresiva apertura a la trascendencia. De este modo, el desarrollo, el progreso, la mirada, la política y la formación se hacen integrales cuando toman en consideración la vocación humana de apertura a la trascendencia y se convierten en cauce para que el ser humano recorra este camino de apertura.

Lo específico de LS en lo relativo al concepto de desarrollo humano integral -y, a nuestro entender, una de sus más brillantes aportaciones-es su puesta en conexión con el ámbito de la ecología, alumbrando así un nuevo concepto en línea con la tradición de la DSI: la ecología integral. Esta propuesta sólo es comprensible desde un planteamiento antropológico que conciba la apertura a la trascendencia como la más genuina vocación del ser humano y el más alto proyecto de desarrollo personal. El papa Francisco expresa esta base antropológica en los números 118 , 119 y 121 de LS. Sin esta base sería imposible construir una ecología integral. Exponemos sucintamente algunas claves de comprensión de esta antropología:

- No hay ecología sin una adecuada antropología (LS 118). Para Francisco, es imposible situar correctamente la relación del ser humano con la naturaleza si previamente no indagamos en profundidad quién es el hombre. Para ello, Francisco denuncia algunos planteamientos extremos (esquizofrénicos, dice en 
el 118), como la negación del valor de los demás seres, la ausencia de reconocimiento de la especificidad del ser humano respecto a las demás criaturas, - determinados planteamientos cientificistas radicales que consideran al ser humano como un mero resultado del azar o del determinismo físico.

- Ecología no es biocentrismo (LS 118). De forma clara, el Papa rechaza un planteamiento donde se ponga en el centro todo lo vivo, sin atender de forma específica al ser humano, con lo que éste tiene de especial dignidad, particular responsabilidad y capacidades específicas como conocimiento, voluntad, libertad y responsabilidad.

- Sólo desde el reconocimiento de lo específico humano y su valoración por encima de las demás criaturas (LS 119) es posible alumbrar relaciones en las que se reconozca al otro y se valore a cada persona. Esto es imprescindible para situar correctamente el concepto de ecología integral. Para que nuestras relaciones con la naturaleza sean adecuadas, no hace falta debilitar la dimensión social del ser humano y tampoco su dimensión trascendente, su apertura al «Tú» divino. Porque no se puede proponer una relación con el ambiente aislada de la relación con las demás personas y con Dios. Sería un individualismo romántico disfrazado de belleza ecológica y un asfixiante encierro en la inmanencia.

Partiendo de esta base antropológica, intentaremos rastrear a lo largo de LS en qué consiste la ecología integral que propone. Ya en el número 10, Francisco hace referencia al Santo de Asís -inspirador, como es bien sabido, de la elección de su nombre como Papa-, a quien propone como ejemplo de una ecología integral. Describe el contenido de dicha ecología integral en San Francisco en el número 11:

Su testimonio nos muestra también que una ecología integral requiere apertura hacia categorías que trascienden el lenguaje de las matemáticas o de la biología y nos conectan con la esencia de lo humano. Así como sucede cuando nos enamoramos de una persona, cada vez que él miraba el sol, la luna o los más pequeños animales, su reacción era cantar, incorporando en su alabanza a las demás criaturas. Él entraba en comunicación con todo lo creado.

De este modo comienza el Papa a decantar el concepto de esta ecología integral: se trata de un modo de mirar la naturaleza que, más allá de conceptos biológicos, técnicos y científicos, nos pone en comunicación con el Creador y en comunidad con todo lo creado. Es decir, una comprensión de la naturaleza como ámbito privilegiado en el que hallar las huellas de lo divino y donde experimentar la armonía con el resto de las criaturas. En definitiva, se trata de una mirada que no 
sólo revela al ser humano su horizonte y su vocación de desarrollo integral, sino que además le posibilita para vivir un encuentro íntimo con el Creador al que le remiten las criaturas.

Desde este punto de partida, el reto que propone Francisco (su llamado) es el de alumbrar una relación con la Naturaleza que permita al hombre un desarrollo que sea-además de integral, en los perfiles y con los matices que hemos mencionado-, sostenible (LS 13 y 18) y solidario (LS 50) ${ }^{5}$.

Esta reflexión es desarrollada específicamente en el capítulo cuarto (Una ecología integral, LS 137 a 162). En estos apartados, el Papa continúa perfilando el concepto de ecología integral, evidenciando dónde se encuentra la novedad y la aportación que ofrece al concepto de desarrollo humano integral. Podríamos caracterizar sucintamente el término ecología integral desde estas claves:

- Se trata de un ideal de desarrollo que incorpora lo humano y lo social (LS 137): vivimos en una sociedad que contamina y que genera exclusión. Ambos aspectos son dos caras de la misma crisis, y exigen una solución integral (LS 139), que sólo puede nacer de un humanismo integral e integrador (LS 141). Se diría que, en este aspecto, el Papa se ampara en la polisemia del término integral para decantar un concepto muy rico de ecología integral: las soluciones deben ser integrales porque deben dar respuesta a las dos caras del problema ecológico (la humana y la social), pero también porque sólo podemos afrontar soluciones a la altura del ser humano si tomamos en consideración la apertura a la trascendencia como horizonte último de desarrollo. Sólo desde la comprensión de este telos en el proceso de desarrollo podremos soñar con nuevas configuraciones sociales, políticas y humanas que hagan compatible el respeto esencial con el medio ambiente y la erradicación de la pobreza.

- La mejora de la calidad de vida debe ser entendida desde una perspectiva integral. Los escenarios en los que transcurre nuestra vida condicionan nuestra manera de vivir, sentir y actuar. Cuando un ambiente es desordenado, caótico - cargado de contaminación visual y acústica, el exceso de estímulos nos desafía a intentar configurar una identidad integrada y feliz (LS 147). Nuestra posibilidad de desarrollo y felicidad, por tanto, está fuertemente vinculada al

${ }^{5}$ La doble exigencia de integralidad y solidaridad en el proceso de desarrollo humano es otro de los temas clásicos en la Doctrina Social de la Iglesia, sintetizado en la expresión inspirada por el dominico francés Louis J. Lebret (1897-1966), quien planteaba la necesidad de alumbrar un desarrollo de todo el hombre (integrall) y de todos los hombres (solidario). Este planteamiento fue muy bien acogido por Juan XXIII, y quedó incorporado a la DSI a partir de Mater et magistra. 
cuidado de nuestro entorno vital, porque nos ofrece el marco por antonomasia para la apertura de nuestra mirada a la huella de lo divino.

- La ecología integral no puede ser separada del ideal del bien común. El Papa expone este planteamiento en el $n^{\circ} 156$, donde aparece formulado en conexión clara con el principio de subsidiariedad. El bien común, según formulación clásica tomada de Gaudium et spes 26, consiste en el conjunto de condiciones que propician el proceso de perfeccionamiento humano 6 . No es concebible, por tanto, un ideal de bien común que no considere de forma clara la importancia del medio ambiente para dotarnos de condiciones que nos permitan abordar un camino de humanización.

- Un planteamiento ecológico integral no puede estar desvinculado de la idea de sostenibilidad, entendida como una búsqueda de justicia inter-generacional (LS 159). Es decir, la justicia y la búsqueda del bien común no están sólo referidos al tiempo presente, sino que requieren una concepción diacrónica de la justicia. Las generaciones futuras merecen recibir el legado de un medio ambiente digno y de calidad, donde también ellos puedan abordar un proceso de desarrollo integral y experimentar la ecología integral propuesta por el Papa como vía de conexión con lo trascendente.

- Por último -y retoma aquí el Papa el contenido más genuino del término ecología integral-, la Encíclica plantea la necesidad de recuperar la serena armonía con la creación, [...] contemplar al Creador, que vive entre nosotros y en lo que nos rodea, cuya presencia no debe ser fabricada sino descubierta, develada.

En definitiva, y a modo de conclusión, la ecología integral es una de las más genuinas aportaciones de la Encíclica y una brillante síntesis de la propuesta que contiene. Ecología integral significa entender la Naturaleza como el lugar privilegiado en el que experimentar la comunión universal que supone el encuentro profundo con el Creador, con toda la familia humana y con cada criatura. De forma tan elocuente como hermosa, el Papa concluye que la ecología integral implica la amorosa conciencia de no estar desconectados de las demás criaturas, de formar con los demás seres del universo una preciosa comunión universal. Para el creyente, el mundo no se contempla desde fuera sino desde dentro, reconociendo los lazos con los que el Padre nos ha unido a todos los seres (LS 220).

${ }^{6}$ La expresión perfeccionamiento, muy frecuentemente utilizada por Juan XXIII, cae prácticamente en desuso con Pablo VI, que prefiere hablar de humanización. 